\title{
Conteúdo de $\beta$-glucana em cultivares de aveia-branca cultivadas em diferentes ambientes
}

\author{
Maraisa Crestani( ${ }^{(1)}$, Fernando Irajá Félix De Carvalho(1), Antonio Costa De Oliveira(1), José Antonio Gonzalez Da Silva(2), \\ Luiz Carlos Gutkoski( ${ }^{(3)}$, João Francisco Sartori(4), Rosa Lía Barbieri(5) e Diego Baretta ${ }^{(1)}$
}

\begin{abstract}
(1)Universidade Federal de Pelotas, Faculdade de Agronomia Eliseu Maciel, Departamento de Fitotecnia, Campus Universitário Capão do Leão, Caixa Postal 354, CEP 96010-900 Pelotas, RS. E-mail: maraisacrestani@gmail.com, carvalho@ufpel.tche.br, acostol@terra.com.br, barettadiego@gmail.com ${ }^{(2)}$ Universidade Regional do Noroeste do Estado do Rio Grande do Sul, Departamento de Estudos Agrários, Rua do Comércio, no 3.000, Bairro Universitário, CEP 98700-000 ljuí, RS. E-mail: jagsfaem@yahoo.com.br (3)Universidade de Passo Fundo, Centro de Pesquisa em Alimentação, Laboratório de Cereais, Campus I, Rodovia BR 285, Km 171, Bairro São José, Caixa Postal 611, CEP 99001-970 Passo Fundo, RS. E-mail: gutkoski@upf.br ${ }^{(4)}$ Fundação Pró-sementes de Apoio à Pesquisa, Rua Diogo de Oliveira, no 640, CEP 99025-130 Passo Fundo, RS. E-mail: sartori@fundacaoprosementes.com.br ${ }^{(5)}$ Embrapa Clima Temperado, Rodovia BR 392, Km 78, Caixa Postal 403, CEP 96001-970, Pelotas, RS. E-mail: barbieri@cpact.embrapa.br
\end{abstract}

Resumo - O objetivo deste trabalho foi caracterizar cultivares de aveia-branca quanto ao conteúdo de $\beta$-glucana nos grãos, determinar sua relação com a produtividade e o rendimento industrial de grãos, e definir os parâmetros de adaptabilidade e estabilidade para esses caracteres. Nas safras de 2007 e 2008, foram cultivadas 15 cultivares de aveia-branca nos municípios de Augusto Pestana, Capão do Leão e Passo Fundo, no Rio Grande do Sul, seguindo delineamento em blocos ao acaso, com quatro repetições constituídas por parcelas úteis de $3 \mathrm{~m}^{2}$. De maneira geral, os genótipos apresentaram desempenho variável de acordo com a região e o ano de cultivo, para conteúdo de $\beta$-glucana no grão. As cultivares Barbarasul, Brisasul, UFRGS 19, UPFA 22, URS 20, URS 22 e URS Guapa apresentam biótipo ideal, com elevado conteúdo médio de $\beta$-glucana no grão, ampla adaptabilidade e elevada estabilidade fenotípica. Foram constatadas relações significativas entre o conteúdo de $\beta$-glucana no grão e a produtividade e o rendimento industrial de grãos.

Termos para indexação: Avena sativa, adaptabilidade, alimento funcional, estabilidade, interação genótipo $\mathrm{x}$ ambiente, qualidade de grão.

\section{$\beta$-glucan content in white oat cultivars grown in different environments}

\begin{abstract}
The objective of this work was to characterize white oat cultivars as to $\beta$-glucan content in grains, to verify its relationship with grain and industrial yield, and to define adaptability and phenotypic stability parameters for these characters. In the 2007 and 2008 seasons, 15 white oat cultivars were grown in Augusto Pestana, Capão do Leão and Passo Fundo municipalities, state of Rio Grande do Sul, Brazil. It was used a randomized complete block design, with four replicates and $3-\mathrm{m}^{2}$ plots. Genotype performance varied according to the region and year of cultivation in relation to $\beta$-glucan content in the grain. The genotypes Barbarasul, Brisasul, UFRGS 19, UPFA 22, URS 20, URS 22 and URS Guapa had an ideal biotype, comprising high mean $\beta$-glucan content, wide adaptability and phenotypic stability. Significant correlations are observed between $\beta$-glucan content and grain and industrial yield.
\end{abstract}

Index terms: Avena sativa, adaptability, functional foods, stability, genotype x environment interaction, grain quality.

\section{Introdução}

No contexto atual da produção agrícola brasileira, é cada vez maior a demanda por cultivares altamente produtivas, que apresentem produtos de elevada qualidade e ampla aceitação comercial. A aveia-branca (Avena sativa L.) tem assumido grande importância como cultura alternativa na estação fria em uma ampla área de cultivo no Brasil, principalmente nos estados do Sul.
A composição química e estrutural do grão da aveia é única entre os cereais, o que lhe confere aptidão para uso na alimentação humana. Entre os componentes das fibras alimentares solúveis presentes no grão de aveia-branca, um dos mais importantes é a $\beta$-glucana $[(1 \rightarrow 3)(1 \rightarrow 4)-\beta$-D-glucana]. A fração $\beta$-glucana, grande responsável por relevantes benefícios à saúde humana, confere a este cereal a condição de alimento 
funcional (FDA Food Labeling, 1997; Brasil, 2009), por contribuir com a redução do colesterol sérico e consequente diminuição dos riscos de enfermidades cardiovasculares (Andon \& Anderson, 2008; Butt et al., 2008).

Trabalhos com a cultura da aveia-branca têm demonstrado a existência de efeitos ambientais significativos sobre o conteúdo de $\beta$-glucana no grão (Lim et al., 1992; de Sá et al., 2000; Doehlert et al., 2001; Beber et al., 2002; Saastamoinen et al., 2004), o que pode dificultar a caracterização e a seleção de genótipos, por exigir testes de desempenho em vários locais e anos de cultivo, na busca de materiais adaptados a maior número de ambientes. No entanto, existe pouca informação na literatura sobre o desempenho das cultivares brasileiras de aveia-branca quanto ao conteúdo de $\beta$-glucana no grão e da influência dos ambientes de cultivo sobre a expressão desse caráter (de Sá et al., 2000; Beber et al., 2002). Assim, a realização de análises de estabilidade e adaptabilidade é importante para o detalhamento das interações genótipo x ambiente, por possibilitar a identificação de cultivares de comportamento previsível e responsivo às variações ambientais (Cruz et al., 2004).

Entre os métodos disponíveis para a identificação da adaptabilidade e da estabilidade de genótipos, a metodologia proposta por Eberhart \& Russel (1966) é uma das mais utilizadas. Na cultura da aveia-branca, esse método tem sido adotado na avaliação do comportamento de cultivares em relação à produtividade de grãos em diferentes ambientes e situações de cultivo (Federizzi et al., 1993; Lorencetti et al., 2002; Benin et al., 2005). Nesse modelo, a análise de adaptabilidade e estabilidade é realizada a partir de equações de regressão linear simples, em que a variável dependente (caráter de interesse) é expressa em função de um índice ambiental que mede a qualidade dos ambientes avaliados. Esse método é apontado como apropriado para estudos com até oito ambientes de cultivo (Cruz et al., 2004). Segundo Eberhart \& Russel (1966), a magnitude e a significância da variância dos desvios da regressão dão uma estimativa da previsibilidade da constituição genética, sendo o genótipo ideal aquele com elevado desempenho médio para o caráter considerado, coeficiente de regressão igual a 1,0 e desvios da regressão iguais a zero.

O conhecimento da variabilidade genética disponível e o comportamento das cultivares de aveia-branca quanto à expressão do conteúdo de $\beta$-glucana no grão são importantes para a adequada recomendação de cultivares com produção de grãos de alta qualidade, destinados à alimentação humana. Além disso, o conhecimento da relação entre o conteúdo de $\beta$-glucana e a produtividade de grãos é importante para a seleção de genótipos de aveia-branca superiores em produtividade e qualidade de grãos.

O objetivo deste trabalho foi caracterizar cultivares de aveia-branca quanto ao conteúdo de $\beta$-glucana nos grãos, verificar sua relação com a produtividade e rendimento industrial de grãos, e definir os parâmetros de adaptabilidade e estabilidade desses caracteres.

\section{Material e Métodos}

Os experimentos foram realizados nas safras agrícolas de 2007 e 2008, nos municípios de Augusto Pestana, $28^{\circ} 27^{\prime} \mathrm{S}, 53^{\circ} 54^{\prime} \mathrm{W}$, altitude de $328 \mathrm{~m}$, Latossolo Vermelho distroférrico típico (Santos et al., 2006); Capão do Leão, $31^{\circ} 45^{\prime} \mathrm{S}, 52^{\circ} 29^{\prime} \mathrm{W}$, altitude de $13 \mathrm{~m}$, Argissolo Vermelho-Amarelo distrófico (Santos et al., 2006) e Passo Fundo, $28^{\circ} 15^{\prime} \mathrm{S}, 52^{\circ} 24^{\prime} \mathrm{W}$, altitude de 687 m, Latossolo Vermelho distrófico típico (Santos et al., 2006), no Rio Grande do Sul (Tabela 1). Foram avaliadas 15 cultivares de aveia-branca recomendadas para o Brasil: UPFA 22, UPF 15, UPF 16, UPF 18, UPFA 20, FAPA Louise, URS 20, URS 21, URS 22, URS Guapa, UFRGS 14, UFRGS 19, Albasul, Barbarasul e Brisasul.

Todos os ensaios foram realizados em delineamento experimental de blocos ao acaso, com quatro repetições, sendo adotada a densidade de 250 sementes viáveis por metro quadrado, com cada repetição formada por parcelas de cinco linhas de $5 \mathrm{~m}$ de comprimento espaçadas em $0,20 \mathrm{~m}$. As medições foram efetuadas no produto obtido com a colheita das três linhas centrais, com parcela útil de $3 \mathrm{~m}^{2}$. Os tratamentos foram caracterizados pelas 15 cultivares de aveia-branca, três locais de cultivo e dois anos (2007 e 2008), e foram avaliados a produtividade de grãos, o rendimento industrial de grãos e o conteúdo de $\beta$-glucana nos grãos.

O preparo do solo das áreas experimentais seguiu as recomendações da Comissão Brasileira de Pesquisa de Aveia (2006), com correção de acidez e adubação com macronutrientes (NPK), realizada de acordo com os teores verificados na análise química do solo 
(Tabela 1), a fim de suprir as exigências da cultura para a produtividade de grãos de aproximadamente $2 \mathrm{Mg} \mathrm{ha}^{-1}$. Nos três locais, os experimentos foram semeados na primeira quinzena de junho, em ambos os anos de avaliação. De acordo com a necessidade de cada local, foi aplicado o fungicida tebuconazole, na dosagem de 0,75 L ha ${ }^{-1}$ (Folicur CE - Bayer CropScience Ltda, São Paulo, Brasil).

Foram estimados a produtividade e o rendimento industrial de grãos das cultivares $\left(\mathrm{kg} \mathrm{ha}{ }^{-1}\right)$. A percentagem de grãos maiores que $2 \mathrm{~mm}$ de espessura foi obtida a partir de uma amostra de cada parcela, com 300 grãos inteiros, peneirados em peneira oblonga. O índice de descasque foi obtido a partir da massa de 300 grãos maiores que $2 \mathrm{~mm}$ de espessura descascados e com casca. O rendimento industrial de grãos foi obtido com a multiplicação da produtividade de grãos $\left(\mathrm{kg} \mathrm{ha}^{-1}\right)$ pela percentagem de grãos maiores que $2 \mathrm{~mm}$ de espessura e pelo índice de descasque, e corresponde à porção de matéria-prima do grão de aveia-branca aproveitada pela indústria de alimentos, em quilograma por hectare.

O conteúdo de $\beta$-glucana foi determinado em amostras de 300 grãos maiores que $2 \mathrm{~mm}$, descascados manualmente, provenientes de cada parcela útil avaliada. As cariopses foram moídas em moinho tipo Willey (Marconi, Piracicaba, Brasil), com peneira de $0,25 \mathrm{~mm}$ de abertura. O material moído foi analisado em espectrômetro do infravermelho proximal (NIRs), modelo 5000 (Perstorp Analytical, Maryland, EUA), no Centro de Pesquisa em Alimentação (Cepa), da Universidade de Passo Fundo. A curva de calibração do teor de $\beta$-glucana no NIRs foi construída pelo Laboratório de Físico-Química do Cepa com o emprego do programa New Infrasoft International Software (Infrasoft International, 1996), pela análise de 100 amostras de aveia-branca, realizada de acordo com a metodologia proposta pela Association of Official Analytical Chemists (1995), método $\mathrm{n}^{\circ}$ 995.16. As análises foram realizadas em triplicata e os resultados de $\beta$-glucana no grão foram expressos em $g$ $100 g^{-1}$.

Foi realizada análise de variância dos dados para identificar os efeitos dos tratamentos cultivar, ano e local, bem como da interação entre os fatores em relação aos caracteres conteúdo $\beta$-glucana nos grãos, produtividade e rendimento industrial de grãos. Os parâmetros de adaptabilidade e estabilidade fenotípica foram estimados pela metodologia de Eberhart \& Russel (1966), baseado na regressão linear, em que tanto os coeficientes de regressão dos valores fenotípicos de cada genótipo em relação ao índice ambiental, quanto os desvios desta regressão proporcionam estimativas de parâmetros de estabilidade e adaptabilidade, de acordo com o seguinte modelo:

$$
\mathrm{Y}_{\mathrm{ij}}=\beta_{\mathrm{oi}}+\beta_{1 \mathrm{i}} \mathrm{I}_{\mathrm{j}}+\delta_{\mathrm{ij}}+\bar{\varepsilon}_{\mathrm{ij}},
$$

em que: $Y_{\mathrm{ij}}$ é a média do genótipo i no ambiente $\mathrm{j}$; $\beta_{\mathrm{oi}}$, média geral do genótipo $\mathrm{i} ; \beta_{1 \mathrm{i}}$, coeficiente de regressão linear, que mede a resposta do i-ésimo genótipo à variação do ambiente; $\mathrm{I}_{\mathrm{j}}$, índice ambiental codificado $\left(\sum \mathrm{I}_{\mathrm{j}}=0\right) ; \delta_{\mathrm{ij}}$, desvios da regressão; e $\bar{\varepsilon}_{\mathrm{ij}}$, erro experimental médio. Foi efetuada a comparação de médias pelo teste Tukey, a 5\% de probabilidade, para comparar o desempenho dos genótipos avaliados nos distintos anos e locais. Para cada ambiente de cultivo, foram estimados os coeficientes de correlação

Tabela 1. Características do solo, e condições climáticas observadas no período de cultivo das cultivares de aveia-branca nos municípios de Augusto Pestana, Capão do Leão e Passo Fundo, no Rio Grande do Sul, em 2007 e $2008^{(1)}$.

\begin{tabular}{|c|c|c|c|c|c|c|c|c|c|}
\hline \multirow[t]{2}{*}{ Localidade } & \multicolumn{5}{|c|}{ Características químicas do solo } & \multicolumn{4}{|c|}{ Condições climáticas } \\
\hline & $\begin{array}{l}\text { Argila } \\
(\%) \\
\end{array}$ & $\begin{array}{l}\text { Índice } \\
\text { SMP }\end{array}$ & $\begin{array}{l}\text { M.O. } \\
(\%) \\
\end{array}$ & $\begin{array}{c}\mathrm{P} \\
-----(\mathrm{m} \\
\end{array}$ & $\left.a^{-3}\right)-----$ & $\begin{array}{l}\text { Temperatura } \\
\text { máxima }\end{array}$ & $\begin{array}{l}\text { Temperatura } \\
\text { mínima }\end{array}$ & $\begin{array}{l}\text { Temperatura } \\
\text { média }\end{array}$ & $\begin{array}{c}\text { Precipitação } \\
\text { acumulada } \\
(\mathrm{mm})\end{array}$ \\
\hline \multicolumn{10}{|c|}{2007} \\
\hline Augusto Pestana & 50,0 & 6,6 & 3,2 & 31,0 & 385,0 & 23,3 & 11,4 & 17,3 & 863,0 \\
\hline Capão do Leão & 24,0 & 6,8 & 2,2 & 29,1 & 143,0 & 19,5 & 10,8 & 15,7 & 798,8 \\
\hline Passo Fundo & 56,0 & 5,4 & 5,5 & 15,0 & 183,8 & 21,3 & 11,3 & 16,3 & 1263,5 \\
\hline \multicolumn{10}{|c|}{2008} \\
\hline Augusto Pestana & 54,0 & 6,2 & 2,9 & 26,0 & 292,0 & 23,1 & 11,3 & 17,2 & $1.042,8$ \\
\hline Capão do Leão & 16,0 & 6,8 & 1,5 & 8,6 & 64,0 & 20,4 & 11,7 & 16,0 & 575,3 \\
\hline Passo Fundo & 46,0 & 6,0 & 3,3 & 5,0 & 204,0 & 20,7 & 11,5 & 16,1 & $1.118,8$ \\
\hline
\end{tabular}

${ }^{(1)}$ Dados referentes ao período de junho a novembro de cada ano. 
fenotípica $\left(\mathrm{r}_{\mathrm{P}}\right)$, genética $\left(\mathrm{r}_{\mathrm{G}}\right)$ e de ambiente $\left(\mathrm{r}_{\mathrm{E}}\right)$ entre o comportamento do conteúdo de $\beta$-glucana no grão e a produtividade e o rendimento industrial de grãos, por meio do método proposto por Steel \& Torrie (1980). A herdabilidade foi calculada no sentido amplo $\left(h_{a}{ }^{2}\right)$ do conteúdo de $\beta$-glucana no grão, em percentagem, pelo uso do quadrado médio esperado [E(QM)], conforme modelo descrito por Carvalho et al. (2001). Todos os procedimentos estatísticos foram efetuados com auxílio do programa Genes (Cruz, 2001).

\section{Resultados e Discussão}

Houve efeitos significativos para os fatores principais genótipo $(\mathrm{G})$, ano (A) e local (L) e para todas as interações testadas, em relação a todos caracteres avaliados (Tabela 2). Os resultados indicam que existe variabilidade entre as cultivares de aveia-branca quanto ao conteúdo de $\beta$-glucana no grão, produtividade e rendimento industrial de grãos, e que o desempenho desses caracteres é afetado de forma diferenciada nos diferentes anos e locais testados. Para o conteúdo de $\beta$-glucana, os quadrados médios para o tratamento local foram maiores, seguidos pelas interações ano $\mathrm{x}$ local e genótipo x local, indício de que, embora as contribuições do ambiente em cada ano de cultivo e do potencial genético sejam importantes, o local de cultivo teve forte influência sobre o conteúdo de $\beta$-glucana do grão.

Ao considerar o conjunto de ambientes, o conteúdo médio de $\beta$-glucana no grão foi de $4,78 \mathrm{~g} 100 \mathrm{~g}^{-1}$, com o desempenho médio das cultivares variando de

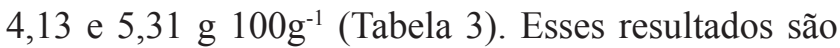
semelhantes aos obtidos por de Sá et al. (2000) e Beber et al. (2002). As estimativas de adaptabilidade $\left(b_{1}\right)$ variaram de 0,53 a 1,77. As cultivares UFRGS 14 e UPF 15, que apresentaram coeficientes $b_{1}$ superiores a $1,0 \quad(\mathrm{p}<0,01)$, mostraram alta responsividade desse caráter à melhoria nas condições ambientais. Em contrapartida, o $b_{1}$ das cultivares UPFA 20 e URS 21 foi de 0,54 e 0,53, respectivamente, demonstrando adaptabilidade a ambientes pouco favoráveis. O coeficiente $b_{1}$ das outras cultivares não diferiu estatisticamente de 1,0 , o que evidencia adaptabilidade ampla, de acordo com o modelo adotado. Os desvios das regressões $\left(\sigma_{\delta \mathrm{i}}^{2}\right)$ foram significativos para as cultivares Albasul, UPF 15, UPF 16 e UPF 18 e são possíveis indicativos de baixa estabilidade em relação à expressão do conteúdo de $\beta$-glucana no grão, ao longo dos anos e locais de cultivo, ou de inadequação do modelo estatístico utilizado. Uma outra possibilidade seria a falha do índice de ambiente na representação do desempenho para esses caracteres (Benin et al., 2005).

Conforme o modelo de Eberhart \& Russel (1966), as cultivares Barbarasul, Brisasul, UFRGS 19, UPFA 22, URS 20, URS 22 e URS Guapa apresentaram biótipo considerado ideal, com elevado conteúdo médio de $\beta$-glucana no grão, coeficiente de regressão igual à unidade e desvios da regressão iguais a zero (Tabela 3).

Tabela 2. Análise de variância para o conteúdo de $\beta$-glucana no grão, a produtividade e o rendimento industrial de grãos, em cultivares de aveia-branca cultivadas nos municípios de Augusto Pestana, Capão do Leão e Passo Fundo, no Rio Grande do Sul, em 2007 e 2008.

\begin{tabular}{|c|c|c|c|c|}
\hline \multirow[t]{2}{*}{ Fonte de Variação } & \multirow[t]{2}{*}{ GL } & \multicolumn{3}{|c|}{ Quadrado médio } \\
\hline & & $\begin{array}{l}\text { Conteúdo de } \beta \text {-glucana } \\
\qquad\left(\mathrm{g} 100 \mathrm{~g}^{-1}\right)\end{array}$ & Produtividade de grãos & Rendimento industrial de grãos \\
\hline$\overline{\text { Genótipo }(\mathrm{G})}$ & 14 & $2,37^{* *}$ & $12.800 .244,00^{* *}$ & $734.797,70^{* *}$ \\
\hline Ano (A) & 1 & $24,52 * *$ & $3.856 .647,00 * *$ & $237.496,70 *$ \\
\hline Local (L) & 2 & $70,47 * *$ & $8.581 .438,00^{* *}$ & $3.378 .329,00 * *$ \\
\hline GxA & 14 & $1,18^{*}$ & $703.763,00 * *$ & $362.211,40 * *$ \\
\hline GxL & 28 & $1,86^{* *}$ & $505.288,40 * *$ & $160.608,40 * *$ \\
\hline $\mathrm{AxL}$ & 2 & $24,72 * *$ & $24.737 .510,00 * *$ & $4.221 .805,00^{* *}$ \\
\hline GxAxL & 28 & $1,32 * *$ & $336.146,00 * *$ & $177.166,90 * *$ \\
\hline Bloco & 3 & 0,88 & $195.193,80$ & $25.905,24$ \\
\hline Residuo & 267 & 0,65 & $159.973,30$ & $55.087,02$ \\
\hline Média & - & 4,78 & $1.784,70$ & 873,59 \\
\hline Desvio padrão & - & 0,81 & 399,97 & 234,71 \\
\hline$\overline{\mathrm{CV}}(\%)$ & - & 16,88 & 22,41 & 26,87 \\
\hline
\end{tabular}

** e *Significativo a $1 \%$ e $5 \%$ de probabilidade, respectivamente, pelo teste $\mathrm{F}$. 
Não houve formação de muitas classes fenotípicas distintas para o conteúdo de $\beta$-glucana no grão, ao se comparar o conjunto das cultivares em cada local e em cada ano de avaliação (Tabela 4). Nos municípios de Capão do Leão, em 2007, e em Passo Fundo, em 2007 e 2008, as cultivares não diferiram estatisticamente entre si. Ao comparar os desempenhos médios gerais para o conteúdo de $\beta$-glucana no grão, em diferentes locais no mesmo ano, Capão do Leão apresentou índices de ambiente positivos, calculados de acordo com o modelo de Eberhart \& Russel (1966).

Trabalhos desenvolvidos no Brasil e em outros países observaram interação significativa entre genótipo $\mathrm{x}$ local x ano (Beber et al., 2002; Saastamoinen et al., 2004) e entre genótipo x ano (Lim et al., 1992; de Sá et al., 2000) na definição fenotípica do conteúdo de $\beta$-glucana no grão, sendo que nesses estudos, os genótipos também apresentaram desempenho variável ao longo de diferentes situações de cultivo, definidas pelas combinações entre os fatores local e ano. Os resultados obtidos no presente trabalho estão de acordo com os que foram obtidos nesses estudos. A existência da interação genótipo $\mathrm{x}$ ambiente torna difícil a eleição de cultivares elite para compor

Tabela 3. Médias gerais $\left(\mathrm{b}_{0}\right)$ para o conteúdo de $\beta$-glucana no grão $\left(\mathrm{g} 100 \mathrm{~g}^{-1}\right)$ e parâmetros de adaptabilidade $\left(\mathrm{b}_{1}\right)$ e estabilidade $\left(\sigma_{\delta i}^{2}\right)$ de acordo com Eberhart \& Russel (1966), em cultivares de aveia-branca, nos municípios de Augusto Pestana, Capão do Leão e Passo Fundo, Rio Grande do Sul, nos anos de 2007 e $2008^{(1)}$.

\begin{tabular}{llccc}
\hline Genótipo & \multicolumn{3}{c}{ Conteúdo de $\beta$-glucana no grão $\left(\mathrm{g} 100 \mathrm{~g}^{-1}\right)$} \\
\cline { 2 - 5 } & \multicolumn{1}{c}{$\mathrm{b}_{0}$} & $\mathrm{~b}_{1}$ & $\sigma_{\delta \mathrm{i}}{ }^{2}$ & $\mathrm{R}^{2}(\%)$ \\
\hline Albasul & $5,31 \mathrm{a}$ & $1,22^{\mathrm{ns}}$ & $0,55^{* *}$ & 65,32 \\
Barbarasul & $4,85 \mathrm{abc}$ & $0,67^{\mathrm{ns}}$ & $0,13^{\mathrm{ns}}$ & 57,78 \\
Brisasul & $5,14 \mathrm{ab}$ & $1,08^{\mathrm{ns}}$ & $-0,09^{\mathrm{ns}}$ & 93,56 \\
FAPA Louise & $4,40 \mathrm{bc}$ & $1,04^{\mathrm{ns}}$ & $-0,16^{\mathrm{ns}}$ & 99,16 \\
UFRGS 14 & $5,10 \mathrm{ab}$ & $1,77^{* *}$ & $0,06^{\mathrm{ns}}$ & 92,67 \\
UFRGS 19 & $4,59 \mathrm{abc}$ & $1,09^{\mathrm{ns}}$ & $0,13^{\mathrm{ns}}$ & 77,85 \\
UPF 15 & $4,13 \mathrm{c}$ & $1,68^{* *}$ & $0,93^{* *}$ & 69,74 \\
UPF 16 & $4,65 \mathrm{abc}$ & $0,98^{\mathrm{ns}}$ & $0,34^{* *}$ & 63,13 \\
UPF 18 & $4,63 \mathrm{abc}$ & $0,77^{\mathrm{ns}}$ & $0,59^{* *}$ & 50,98 \\
UPFA 20 & $4,48 \mathrm{bc}$ & $0,54^{*}$ & $-0,06^{\mathrm{ns}}$ & 71,77 \\
UPFA 22 & $5,00 \mathrm{ab}$ & $0,84^{\mathrm{ns}}$ & $0,03^{\mathrm{ns}}$ & 76,81 \\
URS 20 & $4,84 \mathrm{abc}$ & $1,02^{\mathrm{ns}}$ & $-0,04^{\mathrm{ns}}$ & 88,69 \\
URS 21 & $4,75 \mathrm{abc}$ & $0,53^{*}$ & $-0,11^{\mathrm{ns}}$ & 83,26 \\
URS 22 & $5,04 \mathrm{ab}$ & $0,92^{\mathrm{ns}}$ & $0,14^{\mathrm{ns}}$ & 71,43 \\
URS Guapa & $4,83 \mathrm{abc}$ & $0,86^{\mathrm{ns}}$ & $0,13^{\mathrm{ns}}$ & 69,37 \\
\hline
\end{tabular}

${ }^{(1)}$ Médias seguidas de letras iguais não diferem significativamente entre

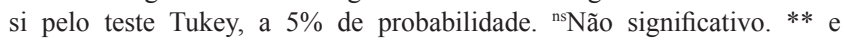
*Significativo a $1 \%$ e $5 \%$ de probabilidade, respectivamente, pelo teste $t$. blocos de cruzamento, com intuito de alcançar elevada qualidade química do grão, assim como a recomendação de cultivares de aveia-branca para diferentes regiões de cultivo. A grande dificuldade está na definição das características do ambiente que interferem de forma significativa sobre a definição fenotípica do conteúdo de $\beta$-glucana no grão, sem que haja um consenso definitivo sobre os fatores

Tabela 4. Médias e índice de ambiente em relação ao conteúdo de $\beta$-glucana no grão $\left(\mathrm{g} 100 \mathrm{~g}^{-1}\right)$, em cultivares de aveia-branca cultivadas nos municípios de Augusto Pestana, Capão do Leão e Passo Fundo, no Rio Grande do Sul, em 2007 e $2008^{(1)}$.

\begin{tabular}{|c|c|c|c|}
\hline \multirow[t]{2}{*}{ Genótipo } & \multicolumn{3}{|c|}{ Conteúdo de $\beta$-glucana no grão $\left({\left.\mathrm{g} 100 \mathrm{~g}^{-1}\right)}^{-1}\right.$} \\
\hline & $\begin{array}{c}\text { Augusto } \\
\text { Pestana }\end{array}$ & $\begin{array}{c}\text { Capão } \\
\text { do Leão }\end{array}$ & $\begin{array}{l}\text { Passo } \\
\text { Fundo }\end{array}$ \\
\hline & \multicolumn{3}{|c|}{ Ano de 2007} \\
\hline Albasul & $6,19 \mathrm{Aa}$ & $6,03 \mathrm{Aa}$ & $3,05 \mathrm{Ba}$ \\
\hline Barbarasul & 4,59Aab & $5,12 \mathrm{Aa}$ & $3,82 \mathrm{Ba}$ \\
\hline Brisasul & $4,71 \mathrm{Bab}$ & $5,57 \mathrm{Aa}$ & $4,07 \mathrm{Ba}$ \\
\hline FAPA Louise & $4,04 \mathrm{ABb}$ & $4,88 \mathrm{Aa}$ & $3,32 \mathrm{Ba}$ \\
\hline UFRGS 14 & $3,87 \mathrm{Bb}$ & $6,18 \mathrm{Aa}$ & $3,86 \mathrm{Ba}$ \\
\hline UFRGS 19 & $3,75 \mathrm{Ab}$ & $4,56 \mathrm{Aa}$ & $3,72 \mathrm{Aa}$ \\
\hline UPF 15 & $3,64 \mathrm{Ab}$ & $4,62 \mathrm{Aa}$ & $3,67 \mathrm{Aa}$ \\
\hline UPF 16 & $4,17 \mathrm{Ab}$ & $5,43 \mathrm{Aa}$ & $2,75 \mathrm{Ba}$ \\
\hline UPF 18 & $5,09 \mathrm{Aab}$ & $5,73 \mathrm{Aa}$ & $3,70 \mathrm{Ba}$ \\
\hline UPFA 20 & $3,83 \mathrm{Ab}$ & $4,66 \mathrm{Aa}$ & $4,08 \mathrm{Aa}$ \\
\hline UPFA 22 & $4,81 \mathrm{ABab}$ & $6,07 \mathrm{Aa}$ & $3,91 \mathrm{Ba}$ \\
\hline URS 20 & $4,48 \mathrm{Aab}$ & $5,44 \mathrm{Aa}$ & $4,19 \mathrm{Aa}$ \\
\hline URS 21 & $4,66 \mathrm{Aab}$ & $4,92 \mathrm{Aa}$ & $4,29 \mathrm{Aa}$ \\
\hline URS 22 & $3,97 \mathrm{Bb}$ & $5,64 \mathrm{Aa}$ & $3,91 \mathrm{Ba}$ \\
\hline URS Guapa & $4,87 \mathrm{ABab}$ & $5,84 \mathrm{Aa}$ & $3,82 \mathrm{Ba}$ \\
\hline Média local & $4,44 \mathrm{~B}$ & $5,38 \mathrm{~A}$ & $3,74 \mathrm{C}$ \\
\hline \multirow[t]{2}{*}{ Indice de ambiente } & $-0,34$ & 0,60 & $-1,04$ \\
\hline & \multicolumn{3}{|c|}{ Ano de 2008} \\
\hline Albasul & $4,62 \mathrm{Ba}$ & $6,44 \mathrm{Aab}$ & $5,52 \mathrm{ABa}$ \\
\hline Barbarasul & $5,07 \mathrm{ABa}$ & $6,04 \mathrm{Aab}$ & $4,50 \mathrm{Ba}$ \\
\hline Brisasul & $4,21 \mathrm{Ba}$ & 6,31Aab & $6,00 \mathrm{Aa}$ \\
\hline FAPA Louise & $3,62 \mathrm{Ba}$ & $5,64 \mathrm{Aab}$ & $4,90 \mathrm{ABa}$ \\
\hline UFRGS 14 & $3,63 \mathrm{Ca}$ & $7,06 \mathrm{Aa}$ & $5,59 \mathrm{Ba}$ \\
\hline UFRGS 19 & $4,07 \mathrm{Ba}$ & $6,44 \mathrm{Aab}$ & $5,00 \mathrm{Ba}$ \\
\hline UPF 15 & $1,98 \mathrm{Cb}$ & $6,48 \mathrm{Aab}$ & $4,97 \mathrm{Ba}$ \\
\hline UPF 16 & $4,93 \mathrm{Aa}$ & $5,44 \mathrm{Ab}$ & $5,19 \mathrm{Aa}$ \\
\hline UPF 18 & $3,20 \mathrm{Bab}$ & $4,53 \mathrm{ABb}$ & $5,52 \mathrm{Aa}$ \\
\hline UPFA 20 & $4,12 \mathrm{Aa}$ & $5,10 \mathrm{Ab}$ & $5,07 \mathrm{Aa}$ \\
\hline UPFA 22 & $4,62 \mathrm{Aa}$ & $5,83 \mathrm{Aab}$ & $4,77 \mathrm{Aa}$ \\
\hline URS 20 & $3,78 \mathrm{Ba}$ & $6,32 \mathrm{Aab}$ & $4,85 \mathrm{Ba}$ \\
\hline URS 21 & $4,11 \mathrm{Aa}$ & $5,30 \mathrm{Ab}$ & $5,26 \mathrm{Aa}$ \\
\hline URS 22 & $4,92 \mathrm{Aa}$ & 5,91Aab & $5,88 \mathrm{Aa}$ \\
\hline URS Guapa & $4,30 \mathrm{Ba}$ & $5,90 \mathrm{Aab}$ & $4,27 \mathrm{Ba}$ \\
\hline Média local & $4,04 \mathrm{C}$ & $5,94 \mathrm{~A}$ & $5,15 \mathrm{~B}$ \\
\hline Índice de ambiente & $-0,74$ & 1,15 & 0,37 \\
\hline
\end{tabular}

Pesq. agropec. bras., Brasília, v.45, n.3, p.261-268, mar. 2010 
de ambiente realmente relevantes, em virtude dos resultados contraditórios apresentados na literatura.

No que se refere à produtividade de grãos, as cultivares Albasul, Barbarasul, Brisasul, FAPA Louise, UFRGS 19, UPF 16 e URS 20 apresentaram adaptabilidade ampla e alta estabilidade fenotípica, mas apenas Barbarasul e Brisasul foram consideradas como possuidoras de um biótipo ideal, por também terem figurado entre as mais produtivas (Tabela 5). Coeficientes $b_{1}$ superiores a 1,0 foram constatados nas cultivares UFRGS 14, URS 22 e URS Guapa, o que evidencia superioridade para o caráter em ambientes favoráveis. Em contrapartida, a cultivar UFPA 22 revelou $b_{1}$ de magnitude inferior à unidade, demonstrando adaptabilidade a ambientes menos favoráveis.

A cultivar URS Guapa mostrou rendimento industrial superior (Tabela 5), e as cultivares Albasul, Barbarasul, UFRGS 19 e URS 20 apresentaram adaptabilidade ampla e estabilidade. Porém, nenhuma apresentou biótipo ideal conforme o modelo de Eberhart \& Russel (1966). As cultivares URS Guapa e UFRGS 14 mostraram desempenho superior em rendimento industrial em ambientes considerados favoráveis, ao passo que, em ambientes desfavoráveis, Brisasul e UPFA 20 mostraram melhor desempenho.

Com base nos coeficientes de correlações fenotípicas $\left(\mathrm{r}_{\mathrm{P}}\right)$, genotípicas $\left(\mathrm{r}_{\mathrm{G}}\right)$ e de ambiente $\left(\mathrm{r}_{\mathrm{E}}\right)$ observados em cada ambiente de cultivo, ao se considerar o comportamento médio e geral dos genótipos em cada ambiente, no Município de Augusto Pestana, em 2007, não foram detectadas relações significativas entre $o$ conteúdo de $\beta$-glucana no grão e produtividade ou rendimento industrial de grãos (Tabela 6). Nos demais ambientes testados, foram detectadas correlações genéticas e fenotípicas positivas. $\mathrm{Na}$ maioria das relações consideradas, foi constatada maior magnitude das correlações genéticas em relação às fenotípicas, o que, de acordo com Peluzio et al. (2005), indica que a expressão fenotípica é diminuída pela influência do ambiente. No entanto, as correlações de ambiente não foram significativas nessa avaliação. De acordo com Falconer (1987), o ambiente caracteriza uma causa de correlação quando dois caracteres são influenciados pelas mesmas diferenças de condições ambientais, sendo a correlação de ambiente resultante do efeito total de todos os fatores variáveis de ambiente. Dessa forma, é possível sugerir que o conteúdo de $\beta$-glucana no grão foi influenciado por condições de ambiente distintas das que influenciaram a expressão da produtividade e rendimento industrial de grãos, o que teria resultado na ausência de correlações de ambiente significativas, nessa avaliação.

Os coeficientes de correlação genética significativos variaram de 0,35 a 0,98 e, de forma geral, as relações entre o conteúdo de $\beta$-glucana no grão e a produtividade

Tabela 5. Médias gerais $\left(b_{0}\right)$ de produtividade e rendimento industrial de grãos $\left(\mathrm{kg} \mathrm{ha}^{-1}\right)$ e parâmetros de adaptabilidade $\left(b_{1}\right)$ e estabilidade $\left(\sigma_{\delta i}^{2}\right)$ segundo Eberhart \& Russel (1966), em cultivares de aveia-branca nos municípios de Augusto Pestana, Capão do Leão e Passo Fundo, Rio Grande do Sul, em 2007 e $2008^{(1)}$.

\begin{tabular}{|c|c|c|c|c|}
\hline Genótipo & $\mathrm{b}_{0}$ & $\mathrm{~b}_{1}$ & $\sigma_{\delta \mathrm{i}}^{2}$ & $\mathrm{R}^{2}(\%)$ \\
\hline & \multicolumn{4}{|c|}{ Produtividade de grãos $\left(\mathrm{kg} \mathrm{ha}^{-1}\right)^{(2)}$} \\
\hline Albasul & $1.661,74 \mathrm{de}$ & $0,96^{\mathrm{ns}}$ & $-27.972,31^{\mathrm{ns}}$ & 95,74 \\
\hline Barbarasul & $1.907,06$ abcde & $1,16^{\mathrm{ns}}$ & $-13.159,51^{\mathrm{ns}}$ & 93,69 \\
\hline Brisasul & $1.887,90 \mathrm{abcd}$ & $0,78^{\mathrm{ns}}$ & $10.024,01^{\mathrm{ns}}$ & 78,13 \\
\hline FAPA Louise & $1.756,99 \mathrm{bcde}$ & $0,92^{\mathrm{ns}}$ & $56.026,51^{\mathrm{ns}}$ & 72,03 \\
\hline UFRGS 14 & $1.927,13 \mathrm{abcd}$ & $1,37^{*}$ & $113.006,40^{* *}$ & 78,30 \\
\hline UFRGS 19 & $1.692,89 \mathrm{de}$ & $0,86^{\mathrm{ns}}$ & $22.504,01^{\mathrm{ns}}$ & 77,79 \\
\hline UPF 15 & $1.598,99 \mathrm{de}$ & $0,96^{\mathrm{ns}}$ & $156.053,20 * *$ & 58,14 \\
\hline UPF 16 & $1.707,67 \mathrm{cde}$ & $1,07^{\mathrm{ns}}$ & $40.834,98^{\mathrm{ns}}$ & 80,56 \\
\hline UPF 18 & $1.375,74 \mathrm{e}$ & $0,67^{\mathrm{ns}}$ & $95.972,72 * *$ & 49,46 \\
\hline UPFA 20 & $1.532,18 \mathrm{de}$ & $0,72^{\mathrm{ns}}$ & $254.370,68 * *$ & 34,22 \\
\hline UPFA 22 & $1.583,79 \mathrm{de}$ & $0,64 *$ & $90.355,40^{*}$ & 47,78 \\
\hline URS 20 & $1.745,79 \mathrm{bcde}$ & $0,91^{\mathrm{ns}}$ & $43.832,80^{\mathrm{ns}}$ & 74,17 \\
\hline URS 21 & $2.116,85 \mathrm{ab}$ & $1,07^{\mathrm{ns}}$ & $81.507,39^{*}$ & 73,62 \\
\hline URS 22 & $2.096,46 \mathrm{abc}$ & $1,47 * *$ & $188.044,39 * *$ & 73,66 \\
\hline \multirow[t]{2}{*}{ URS Guapa } & $2.179,36 \mathrm{a}$ & $1,43^{* *}$ & $88.096,23^{*}$ & 82,39 \\
\hline & \multicolumn{4}{|c|}{ Rendimento industrial de grãos $\left(\mathrm{kg} \mathrm{ha}^{-1}\right)^{(3)}$} \\
\hline Albasul & $738,09 \mathrm{def}$ & $0,77^{\mathrm{ns}}$ & $-6.894,10^{\mathrm{ns}}$ & 84,71 \\
\hline Barbarasul & $964,80 \mathrm{bcd}$ & $1,07^{\mathrm{ns}}$ & $11.493,69^{\mathrm{ns}}$ & 74,48 \\
\hline Brisasul & $878,25 \mathrm{bcd}$ & $0,49 *$ & $642,03^{\mathrm{ns}}$ & 51,67 \\
\hline FAPA Louise & $646,20 \mathrm{ef}$ & $0,64^{\mathrm{ns}}$ & $138.779,64 * *$ & 14,60 \\
\hline UFRGS 14 & $1.057,84 \mathrm{~b}$ & $1,59 *$ & $54.534,47 * *$ & 70,52 \\
\hline UFRGS 19 & $806,48 \mathrm{cdef}$ & $1,10^{\mathrm{ns}}$ & $-23.353,04^{\mathrm{ns}}$ & 87,12 \\
\hline UPF 15 & $748,16 \mathrm{cdef}$ & $1,02^{\mathrm{ns}}$ & $40.722,02 * *$ & 54,93 \\
\hline UPF 16 & 853,77 bcde & $1,26^{\mathrm{ns}}$ & $29.251,71 *$ & 70,29 \\
\hline UPF 18 & $621,55 f$ & $0,74^{\mathrm{ns}}$ & $21.029,21 *$ & 50,36 \\
\hline UPFA 20 & $755,66 \mathrm{cdef}$ & $0,21 * *$ & $61.605,43 * *$ & 3,72 \\
\hline UPFA 22 & 822,41 cdef & $0,92^{\mathrm{ns}}$ & $26.749,92 *$ & 57,47 \\
\hline URS 20 & $953,91 \mathrm{bcd}$ & $1,05^{\mathrm{ns}}$ & $14.687,04^{\mathrm{ns}}$ & 71,41 \\
\hline URS 21 & $978,02 \mathrm{bc}$ & $1,06^{\mathrm{ns}}$ & $32.622,26^{*}$ & 61,12 \\
\hline URS 22 & $970,58 \mathrm{bc}$ & $1,00^{\mathrm{ns}}$ & $80.172,32 * *$ & 40,69 \\
\hline URS Guapa & $1.308,14 \mathrm{a}$ & $2,08 * *$ & $22.329,57^{*}$ & 88,48 \\
\hline
\end{tabular}

${ }^{(1)}$ Médias seguidas de letras iguais não diferem significativamente entre si pelo teste Tukey, a 5\% de probabilidade. ${ }^{(2)}$ Os índices de ambiente para o caráter produtividade de grãos, nos municípios de Augusto Pestana, Capão do Leão e Passo Fundo, foram, respectivamente, de -243,18, -175,85, 108,54, em 2007, e de 658,38, 364,17 e -712,04, em 2008. ${ }^{(3)}$ Os índices de ambiente para o caráter rendimento industrial de grãos, nos municípios de Augusto Pestana, Capão do Leão e Passo Fundo foram, respectivamente, de $-86,67,113,82,49,91$, em de 2007 , e de $169,90,172,31$ e $-419,27$, em 2008. ns Não significativo. ** e *Significativo a $1 \%$ e $5 \%$ de probabilidade, respectivamente, pelo teste $t$. 
Tabela 6. Herdabilidade $\left(\mathrm{h}^{2}\right)$ do caráter conteúdo de $\beta$-glucana no grão $\left(\mathrm{g} 100 \mathrm{~g}^{-1}\right)$ e suas correlações fenotípicas, genéticas e de ambiente com a produtividade $\left(\mathrm{kg} \mathrm{ha}^{-1}\right)$ e o rendimento industrial de grãos $\left(\mathrm{kg} \mathrm{ha}^{-1}\right)$, em cultivares de aveia-branca, nos municípios de Augusto Pestana, Capão do Leão e Passo Fundo, no Rio Grande do Sul, em 2007 e 2008.

\begin{tabular}{|c|c|c|c|c|c|c|}
\hline \multirow[t]{2}{*}{ Parâmetro $^{(1)}$} & \multicolumn{2}{|c|}{ Augusto Pestana } & \multicolumn{2}{|c|}{ Capão do Leão } & \multicolumn{2}{|c|}{ Passo Fundo } \\
\hline & 2007 & 2008 & 2007 & 2008 & 2007 & 2008 \\
\hline & \multicolumn{6}{|c|}{ Produtividade de grãos $\left(\mathrm{kg} \mathrm{ha}^{-1}\right)$} \\
\hline Correlação fenotípica $\left(r_{p}\right)$ & $0,11^{\mathrm{ns}}$ & $0,50 * *$ & $0,29 * *$ & $0,37 * *$ & $0,32 * *$ & $0,33 * *$ \\
\hline Correlação genética $\left(\mathrm{r}_{\mathrm{G}}\right)$ & $0,13^{\mathrm{ns}}$ & $0,63 * *$ & $0,37 * *$ & $0,56 * *$ & $0,91 * *$ & $0,98 * *$ \\
\hline \multirow[t]{2}{*}{ Correlação de ambiente $\left(\mathrm{r}_{\mathrm{E}}\right)$} & $0,08^{\text {ns }}$ & $-0,21^{\mathrm{ns}}$ & $0,09^{\mathrm{ns}}$ & $-0,14^{\mathrm{ns}}$ & $-0,06^{\mathrm{ns}}$ & $0,01^{\mathrm{ns}}$ \\
\hline & \multicolumn{6}{|c|}{ Rendimento industrial de grãos $\left(\mathrm{kg} \mathrm{ha}^{-1}\right)$} \\
\hline Correlação fenotípica $\left(r_{p}\right)$ & $-0,04^{\mathrm{ns}}$ & $0,42 * *$ & $0,27 * *$ & $0,26 * *$ & $0,39 * *$ & $0,27^{*}$ \\
\hline Correlação genética $\left(\mathrm{r}_{\mathrm{G}}\right)$ & $-0,08^{\mathrm{ns}}$ & $0,48 * *$ & $0,35^{* *}$ & $0,39 * *$ & $0,95 * *$ & $0,81^{* *}$ \\
\hline Correlação de ambiente $\left(\mathrm{r}_{\mathrm{E}}\right)$ & $0,04^{\mathrm{ns}}$ & $-0,06^{\mathrm{ns}}$ & $0,06^{\mathrm{ns}}$ & $-0,22^{\mathrm{ns}}$ & $0,05^{\mathrm{ns}}$ & $0,09^{\mathrm{ns}}$ \\
\hline $\mathrm{h}^{2}(\%)$ & 50,28 & 83,12 & 61,59 & 66,07 & 13,44 & 20,59 \\
\hline
\end{tabular}

${ }^{(1)}$ As correlações apresentaram 58 graus de liberdade (n-2). ns Não significativo. ${ }^{* *}$ e *Significativo a $1 \%$ e $5 \%$ de probabilidade, respectivamente, pelo teste t.

foram superiores às correlações com o rendimento industrial (Tabela 6). No cultivo em Passo Fundo, em 2007, a magnitude da correlação genética entre o conteúdo de $\beta$-glucana no grão e a produtividade $\left(\mathrm{r}_{\mathrm{G}}=0,91\right)$ foi inferior à correlação com o rendimento industrial $\left(\mathrm{r}_{\mathrm{G}}=0,95\right)$, o que caracteriza uma exceção ao comportamento geral. Caracteres com correlação fenotípica e genotípica alta podem ser considerados para seleção. Contudo, somente as correlações genéticas são de natureza herdável, e podem contribuir efetivamente para a orientação dos programas de melhoramento (Cruz et al., 2004). Deste modo, a seleção indireta para o conteúdo de $\beta$-glucana no grão, efetuada com base na produtividade, pode ser mais eficiente do que a efetuada com base no rendimento industrial.

As correlações genéticas constatadas em Augusto Pestana, em 2008, e Capão do Leão, em 2007 e 2008, foram intermediárias $\left(\mathrm{r}_{\mathrm{G}}=0,35\right.$ à 0,63$)$, enquanto em Passo Fundo, em 2007 e 2008, foram altas $\left(\mathrm{r}_{\mathrm{G}}=0,81\right.$ à 0,98$)$. Contudo, não é possível afirmar que a seleção para o conteúdo de $\beta$-glucana será mais eficiente quando efetuada com base na produtividade de grãos ou no rendimento industrial em Passo Fundo, em comparação às demais localidades testadas, uma vez que, nesse local, foram detectadas as menores magnitudes da herdabilidade para esse caráter (Tabela 6). A expressão para o conteúdo de $\beta$-glucana no grão sofreu menor interferência do ambiente em Capão do Leão e Augusto Pestana, nos dois anos de avaliação. A variabilidade observada nos índices de herdabilidade é reflexo da diversidade das condições ambientais testadas. As evidências de que o conteúdo de $\beta$-glucana no grão em aveia-branca corresponde a um caráter poligênico com efeito aditivo, em que o ambiente contribui de maneira variável na definição fenotípica (Kianian et al., 2000; Cervantes-Martinez et al., 2001) são fatores que contribuem para esse resultado.

\section{Conclusões}

1. O conteúdo de $\beta$-glucana no grão de aveia-branca varia de acordo com os ambientes e anos de cultivo.

2. As cultivares Barbarasul, Brisasul, UFRGS 19, UPFA 22, URS 20, URS 22 e URS Guapa apresentam biótipos considerados ideais para o conteúdo de $\beta$-glucana, com adaptabilidade ampla e elevada estabilidade fenotípica.

3. Existem associações significativas entre $o$ conteúdo de $\beta$-glucana e a produtividade e o rendimento industrial de grãos, para a maioria dos ambientes testados.

\section{Referências}

ANDON, M.B.; ANDERSON, J.W.A. The oatmeal-cholesterol connection: 10 years later. American Journal of Lifestyle Medicine, v.2, p.55-57, 2008.

ASSOCIATION OF OFFICIAL ANALYTICAL CHEMISTS. Official methods of analysis of the Association of Official Analytical Chemists. $16^{\text {th }}$ ed. Arlington: AOAC International, 1995. 2v.

BEBER, R.C.; DE FRANCISCO, A.; ALVES, A.C.; SÁ, R.M. de; OGLIARI, P. Caracterização química de genótipos brasileiros de aveia (Avena sativa L.). Acta Científica Venezolana, v.53, p.202-209, 2002.

BENIN, G.; CARVALHO, F.I.F. de; OLIVEIRA, A.C.; LORENCETTI, C.; VIEIRA, E.A.; COIMBRA, J.L.M.; VALÉRIO, I.P.; FLOSS, E.L.; BERTAN, I.; SILVA, G.O. da. Adaptabilidade e 
estabilidade em aveia em ambientes estratificados. Ciência Rural, V.35, p.295-302, 2005.

BRASIL. Ministério da Saúde. Agência Nacional de Vigilância Sanitária. Comissões tecnocientíficas de assessoramento em alimentos funcionais e novos alimentos. II. Resoluções ANVS/MS n. ${ }^{\circ}$ 16, 17, 18 e 19/99. Disponível em: <http://www. anvisa.gov.br/alimentos/comissoes/tecno_bk.htm>. Acesso em: 1 out. 2009

BUTT, M.S.; TAHIR-NADEEM, M.; KHAN, M.K.I.; SHABIR, R.; BUTT, M.S.A. Oat: unique among the cereals. European Journal of Nutrition, v.47, p.68-79, 2008.

CARVALHO, F.I.F. de; SILVA, S.A.; KUREK, A.J.; MARCHIORO, V.S. Estimativas e implicações da herdabilidade como estratégia de seleção. Pelotas: UFPel, 2001. 99p.

CERVANTES-MARTINEZ, C.T.; FREY, K.J.; WHITE, P.J.; WESENBERG, D.M.; HOLLAND, J.B. Selection for greater $\beta$-glucan content in oat grain. Crop Science, v.41, p.1085-1091, 2001.

COMISSÃO BRASILEIRA DE PESQUISA DE AVEIA. Indicações técnicas para cultura da aveia. Guarapuava: Fundação Agrária de Pesquisa Agropecuária, 2006. 82p.

CRUZ, C.D. Programa GENES: versão Windows: aplicativo computacional em genética e estatística. Viçosa: UFV, 2001. 648p.

CRUZ, C.D.; REGAZZI, A.J.; CARNEIRO, P.C.S. Modelos biométricos aplicados ao melhoramento genético. Viçosa: UFV, 2004. 480p.

DE SÁ, R.M. de; DE FRANCISCO, A.; OGLIARI, P.J.; BERTOLDI, F.C. Variação no conteúdo de beta-glucanas em cultivares brasileiros de aveia. Ciência e Tecnologia de Alimentos, v.20, p.99-102, 2000.

DOEHLERT, D.C.; MCMULLEN, M.S.; HAMMOND, J.J. Genotypic and environmental effects on grain yield and quality of oat grown in North Dakota. Crop Science, v.41, p.1066-1072, 2001.

EBERHART, S.A.; RUSSELL, W.A. Stability parameters for comparing varieties. Crop Science, v.6, p.36-40, 1966.

FALCONER, D.S. Introdução à genética quantitativa. Viçosa: UFV, 1987. 279p.
FDA FOOD LABELING. Health claims: oats and coronary disease. Federal Register, v.62, p.3583-3601, 1997.

FEDERIZZI, L.C.; BARBOSA NETO, J.F.; CARVALHO, F.I.F. de; VIAU, L.V.M.; SEVERO, J.L.; FLOSS, E.L.; ALVES, A.; ALMEIDA, J.; SILVA, A.C. Estabilidade do rendimento de grãos em aveia: efeito do uso de fungicidas. Pesquisa Agropecuária Brasileira, v.28, p.465-472, 1993.

INFRASOFT INTERNATIONAL. NIRSystems: routine operation and calibration development manual. Version 4.0. Washington: ISI, 1996. 378p.

KIANIAN, S.F.; PHILLIPS, R.L.; RINES, H.W.; FULCHER, R.G.; WEBSTER, F.H.; STUTHMAN, D.D. Quantitative trait loci influencing $\beta$-glucan content in oat (Avena sativa, $2 \mathrm{n}=6 \mathrm{x}=42$ ). Theoretical and Applied Genetics, v.101, p.1039-1048, 2000.

LIM, H.S.; WHITE, P.J.; FREY, K.J. Genotipic effects on $\beta$-glucan content of oat lines grown in two consecutive years. Cereal Chemistry, v.69, p.262-265, 1992.

LORENCETTI, C.; CARVALHO, F.I.F.; ALMEIDA, J.L.; MARCHIORO, V.S.; BENIN, G.; HARTWIG, I. Adaptabilidade e estabilidade de rendimento de grão em aveia hexaplóide. Pesquisa Agropecuária Gaúcha, v.8, p.83-91, 2002.

PELUZIO, J.M.; ALMEIDA, R.D. de; FIDELIS, R.R.; ALMEIDA JÚNIOR, D.; BRITO, É.L.; FRANCISCO, E.R. Correlação entre caracteres de soja, em Gurupi, Tocantins. Revista Ceres, v.52, p.779-786, 2005 .

SAASTAMOINEN, M.; HIETANIEMI, V.; PIHLAVA, J.M.; EUROLA, M.; KONTTURI, M.; TUURI, H.; NISKANEN, M.; KANGAS, M.N.A. $\beta$-glucan contents of groats of different oat cultivars in official variety, in organic cultivation, and in nitrogen fertilization trials in Finland. Agricultural and Food Science, v.13, p.68-79, 2004.

SANTOS, H.G. dos; JACOMINE, P.K.T.; ANJOS, L.H.C. dos; OLIVEIRA, V.A. de; OLIVEIRA, J.B. de; COELHO, M.R.; LUMBRERAS, J.F.; CUNHA, T.J.F. (Ed.). Sistema brasileiro de classificação de solos. Rio de Janeiro: Embrapa Solos, 2006. 306p.

STEEL, R.G.D.; TORRIE, J.H. Principles and procedures of statistics: a biometrical approach. $2^{\text {nd }}$ ed. New York: McGraw-Hill, 1980. 631p.

Recebido em 17 de dezembro de 2009 e aprovado em 5 de janeiro de 2010 